\title{
A rapid spectroscopic method to detect the fraudulent treatment of tuna fish with carbon monoxide
}

\author{
Giulietta Smulevich ${ }^{\mathrm{a}, *}$, Enrica Droghetti ${ }^{\mathrm{a}}$, Claudia Focardi ${ }^{\mathrm{b}}$, Massimo Coletta ${ }^{\mathrm{c}}$, \\ Chiara Ciaccio ${ }^{\mathrm{c}}$, Mila Nocentini ${ }^{\mathrm{b}}$ \\ a Dipartimento di Chimica, Università di Firenze, Via della Lastruccia 3, I-50019 Sesto Fiorentino (FI), Italy \\ ${ }^{\mathrm{b}}$ Istituto Zooprofilattico Sperimentale delle Regioni Lazio e Toscana, Via di Castelpulci, 41, I-50010 San Martino alla Palma (FI), Italy \\ c Dipartimento di Medicina Sperimentale e Scienze Biochimiche, Università di Roma Tor Vergata, Via Montpellier 1, I-00133 Roma, Italy
}

Received 10 October 2005; received in revised form 23 February 2006; accepted 4 March 2006

\begin{abstract}
Carbon monoxide $(\mathrm{CO})$ can be used to treat fresh meat and fish in order to retain its 'fresh' red colour appearance for a longer period of time. In fact, upon aging, myoglobin is oxidized to met-myoglobin with the concomitant blue-shift and broadening of the Soret maximum, which brings about a change in the colour of the fish, revealing that it is no longer fresh. The use of carbon monoxide, which reacts with the oxy-myoglobin to form a fairly stable cherry red carboxy-myoglobin complex may mask spoilage, because the CO-complex can be stable beyond the microbiological shelf life of the meat. The presence of $\mathrm{CO}$ in tuna fish has been investigated by optical spectroscopy as the formation of the $\mathrm{CO}$ adduct can be easily detected by the combined analysis of electronic absorption spectra in their normal and second derivative modes, monitoring the intense Soret band at $420 \mathrm{~nm}$. The presence of met- and oxy-myoglobin can obscure the presence of small amounts of the $\mathrm{CO}$ adduct; however, it can be revealed by chemically reducing the met- and oxy-forms to the deoxy-form in an anaerobic environment. This spectroscopic method provides a qualitatively rapid laboratory screening procedure for food control to unmask the presence of $\mathrm{CO}$ in frozen or fresh fish.
\end{abstract}

(c) 2006 Elsevier Ltd. All rights reserved.

Keywords: Myoglobin-CO complex; Electronic absorption; Second derivative; Tuna fish

\section{Introduction}

The freshness of tuna meat and more generally of any kind of meat, is normally judged by its bright red colour. The desirable bright red colour is due to the presence of oxygenated myoglobin, which is present in the red muscle fibres. Myoglobin $(\mathrm{Mb})$ is a heme enzyme essential for the storage of oxygen in the muscles of live animals. However, the amount of $\mathrm{Mb}$ varies as a function of the tuna's age, physical activity and species as well as the way the meat is treated (Giddings, 1974; Livingston \& Brown, 1981). When the fish is cut up, oxygen comes into contact

\footnotetext{
${ }^{*}$ Corresponding author. Tel.: +39 0554573083; fax: +39 0554573077.

E-mail address: Giulietta.smulevich@unifi.it (G. Smulevich).
}

with $\mathrm{Mb}$ in the exposed tuna meat surface. The oxygen is absorbed and reacts with the myoglobin to form a bright red pigment (oxy-myoglobin) which brings about the attractive red colour of fresh tuna meat. However, with storage over a period of time and continued exposure to oxygen, the red colour of the meat gradually changes into various shades of brown due to oxidation and conversion of the oxy-myoglobin $\left(\mathrm{Fe}^{2+}-\mathrm{O}_{2}\right)$ to the brown ferric $\left(\mathrm{Fe}^{3+}\right)$ met-myoglobin (Tajima \& Shikama, 1987).

Colour is the most important sensory attribute for consumer decisions on the purchase of fresh meat. In order to retain its 'fresh' red colour for a longer period of time, carbon monoxide $(\mathrm{CO})$ gas has been used to treat meat in the modified atmosphere packaging (MAP) system. The carbon monoxide reacts with the oxy-myoglobin to form a very stable carboxy-myoglobin complex (CO-Mb) as the 
partition coefficient for $\mathrm{CO}$ is about 50 -fold higher than that of oxygen (Antonini \& Brunori, 1971). Many reports have been published on the use of the MAP technique to prolong the microbiological shelf life of meat and to maintain its attractive red colour (Lunõ, Roncales, Djenane, \& Beltrán, 2000). Due to the high stability of the CO-Mb complex, only relatively low levels of $\mathrm{CO}(<1 \%)$ are needed in order to maintain the red colour of meat (Sørheim, Nissen, \& Nesbakken, 1999). However, CO may mask spoilage, because the stable cherry red colour can last beyond the microbiological shelf life of the meat. For this reason the use of CO in MAP is not allowed in the USA and EU. Recently, frozen yellowfin tuna loins (Thunnus Albacares) of Indonesia provenience, with the characteristic cherry red colour due to treatment with $\mathrm{CO}$, have been introduced in the EU market. In accordance to the EU Regulation No. 178/2002 a rapid alert system has been notified on those products, due to the risk related to the presence of $\mathrm{CO}$.

There are no direct health implications from eating CO-treated tuna. However, since CO treatment makes tuna appear fresh, CO-treated tuna can obscure the colour changes, which normally follow aging of the fish, so the real health risk is due to the lack of freshness of the product. In this respect, it has to be considered that tuna fish, like other Scombroid fishes, is most commonly associated with incidents of histamine intoxication. Histamine can be formed by oxidative decarboxylation of histidine, and such fishes contain in the red muscles a high quantity of histidine from $1 \mathrm{~g} / \mathrm{Kg}$ in herring to $15 \mathrm{~g} / \mathrm{Kg}$ in tuna. This process, associated with decarboxylase-positive microorganisms, can be fast if the storage conditions are inadequate (Shalaby, 1997; Silla Santos, 1996). Moreover, secondary amines, such as cadaverine and putresceine, can be produced in the catabolism of histamine, which can react with nitrite to form heterocyclic carcinogenic nitrosamines. Although histamine is the most toxic amine detected in food, the toxicological effect depends on histamine intake concentration, the presence of other amines and individual characteristics, like aminooxidase activity. The level of $1000 \mathrm{mg} / \mathrm{kg}$ is considered dangerous for health. The European Union, with the Directive 91/493/CEE, has established that the average content of histamine, for some fish species, should not exceed $10-20 \mathrm{mg} / 100 \mathrm{~g}$ of fish.

A variety of methods are available for the analysis of $\mathrm{CO}$ in food materials and in blood, particularly in the field of forensic science, including spectrophotometric methods (Bylkas \& Andersson, 1997; Cruz, López-Rivadulla, Sánchez, Bermejo, \& Fernández, 1993; Sano \& Hashimoto, 1958; Wolfe, Watts, \& Brown, 1978), infrared analysis and gas chromatography (Lewis, Johnson, \& Canfield, 2004; Oritani et al., 2000). Commonly in forensic science (Beutler \& West, 1984; Levine, D’Nicuola, Kunsman, Smith, \& Stahl, 1996) a spectrophotometric method is used to determine the presence of CO-hemoglobin. However, it is considered essential to confirm the result with a second technique based on a different analytical principle, like gas chromatography. Recently, a simple, confirmative method for quantitative determination of carbon monoxide in commercially treated tuna and mahi-mahi tissues has been reported using gas chromatography/mass spectrometry, following chemical liberation of $\mathrm{CO}$ (Anderson $\& \mathrm{Wu}, 2005$ ). The official laboratories of food control need not only confirmatory methods but also rapid low cost screening methods for everyday activity. Therefore, the aim of the present study was to develop a rapid, simple spectrophotometric method to detect the presence of carbon monoxide in CO-treated tuna fish, which might be useful as a screening method for determining the presence of $\mathrm{CO}$ in food products, which are not labelled as such. An effective procedure has been established based on the combined analysis of electronic absorption spectra in their normal and second derivative modes, allowing us to discriminate between treated and non-CO-treated (untreated) samples, and to calculate the fraction of $\mathrm{CO}$ $\mathrm{Mb}$ in meat drip.

\section{Materials and methods}

\subsection{Purification of myoglobin}

$\mathrm{Mb}$ was purified according to a procedure described previously (Wittenberg \& Wittenberg, 1981). A slice of tuna meat of about $150 \mathrm{~g}$ was homogenized in 2 volumes of physiological solution $0.7 \% \mathrm{NaCl}$ and then centrifuged at 1700 r.p.m. for $20 \mathrm{~min}$ (at $T=10^{\circ} \mathrm{C}$ ) using a Megafuge $1.0 \mathrm{R}$. The cloudy red supernatant was saved, diluted in 3 volumes of washing solution $\left(155 \mathrm{mM} \mathrm{NH}_{4} \mathrm{Cl}, 10 \mathrm{mM}\right.$ $\mathrm{Na}_{2} \mathrm{CO}_{3}$, and $0.1 \mathrm{mM}$ EDTA) and centrifuged again at 10,000 r.p.m. for $30 \mathrm{~min}$ (at $T=10^{\circ} \mathrm{C}$ ) to remove any residual solids.

The separation of $\mathrm{Mb}$ from hemoglobin $(\mathrm{Hb})$ was then achieved using gel filtration chromatography with a Sephadex G-100 superfine column $(2.5 \mathrm{~cm} \times 1 \mathrm{~m}$, with a bed volume of about $300 \mathrm{ml}$ ), equilibrated and eluted with potassium phosphate buffer $50 \mathrm{mM}, \mathrm{pH} 7.4 .10 \mathrm{ml}$ of $\mathrm{Hb}-\mathrm{Mb}$ solution were diluted in $20 \mathrm{ml}$ of potassium phosphate buffer $50 \mathrm{mM}, \mathrm{pH} 7$, sodium dithionite was added to a concentration of $1 \mathrm{mg} / \mathrm{ml}$, then the sample was poured on top of the column, which was eluted at a flow rate of $1 \mathrm{ml} /$ min. $3.5 \mathrm{ml}$ fractions were collected and assayed spectrophotometrically from 350 to $600 \mathrm{~nm}$ using a Jasco V-530 spectrophotometer. $\mathrm{Hb}$ should elute first followed by $\mathrm{Mb}$, but in our case no detectable protein was observed besides $\mathrm{Mb}$ and from the chromatographic pattern the $\mathrm{Hb}$ concentration was lower than $3 \%$ of the total sample.

The Mb-containing fractions were pooled and concentrated to 5-10 ml over a YM-10 membrane (Amicon) and stored at $4{ }^{\circ} \mathrm{C}$. The $\mathrm{Mb}$ obtained was pure, as indicated by the absorption spectrum, which showed a $A_{414} / A_{280}$ ratio (purity index) of about 0.8 . Protein concentration was obtained by measuring the absorbance at $414 \mathrm{~nm}$ using 
the extinction coefficient of $128 \mathrm{mM}^{-1} \mathrm{~cm}^{-1}$ (Antonini \& Brunori, 1971).

\subsection{Sample preparation}

Reference sample. Reference samples were obtained as previously reported (Verde et al., 2004). The oxy- derivative of $\mathrm{Mb}$ was prepared by reducing purified $\mathrm{Mb}$ with $5 \mu 1$ of $(20 \mathrm{mg} / \mathrm{ml})$ freshly prepared solution of sodium dithionite (Sigma) for $2 \mathrm{ml}$ of $\mathrm{Mb}$ solution and then filtering through a Biogel P6DG (Bio-Rad) column equilibrated with phosphate buffer, $\mathrm{pH}$ 7.0. The ferric met-Mb derivative was prepared by oxidation of the oxy-Mb with an approximately 3-fold excess of potassium ferricyanide (Sigma), followed by gel filtration on a Biogel P6DG column equilibrated with the phosphate buffer to remove the oxidant. The deoxy-Mb was prepared by adding $5 \mu \mathrm{l}$ of sodium dithionite $(20 \mathrm{mg} / \mathrm{ml})$ to $2 \mathrm{ml}$ of deoxygenated buffered solution of met-Mb. CO-Mb was prepared by flushing met-Mb with nitrogen, then with $\mathrm{CO}$ (Rivoira) and reducing the protein as described above.

Fortified samples. Three different portions of meat drip from fresh tuna fish fillet were flushed with $\mathrm{CO}$ for a few seconds and then reduced with dithionite to obtain a partial CO-complexed $\mathrm{Mb}$.

Routine samples. To avoid significant loss of $\mathrm{CO}$, frozen yellowfin tuna loins (Thunnus albacares), imported from Indonesia and under EU alert notification for suspect carbon monoxide treatment, were defrosted in the sealed package. The meat drip was collected by using a gastight syringe, placed in a $1 \mathrm{~cm}$ path quartz cuvette and then diluted to $2 \mathrm{ml}$ with deoxygenated $100 \mathrm{mM}$ phosphate buffer $\mathrm{pH}$ 7.0. Electronic absorption spectra were collected on the raw materials and after addition of 5-10 $\mu 1$ of sodium dithionite $(20 \mathrm{mg} / \mathrm{ml})$.

Spectra of non-CO-treated meat drip from fresh yellowfin tuna loins fished in the Mediterranean sea along the Sardinia coast (Italy) were also collected for comparison.

\subsection{Spectroscopy}

Electronic absorption spectra of the various $\mathrm{Mb}$ samples were measured with a Cary 5 spectrophotometer. The spectra were recorded from 300 to $700 \mathrm{~nm}$ at the scanning rate of $100 \mathrm{~nm} / \mathrm{min}$. The spectra were baseline corrected when necessary second derivative spectra were obtained using the Lab Calc program (Galactic Industries Corp.). For the derivatization process, the Savitzky-Golay method was applied using 15 data points. No changes in the wavenumber or in the bandwidth were observed when the number of points was increased or decreased.

\section{Quantitative analysis}

The UV-Vis spectra of the reference samples ( $r$ ) of tuna $\mathrm{Mb}$ in their deoxy- and CO-bound forms are reported in

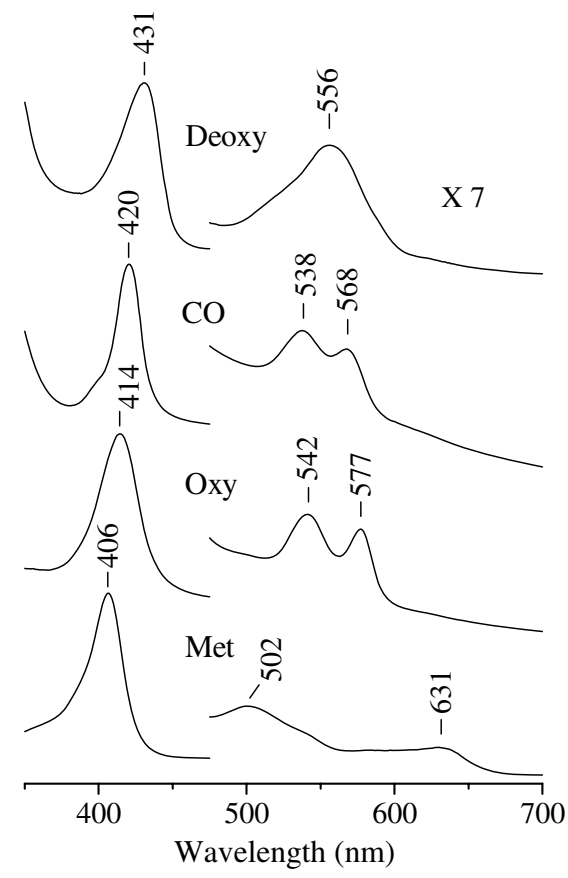

Fig. 1. Absorption and second derivative spectra of the met-, oxy-, CO-, and deoxy-myoglobin purified from tuna fish. The $475-700 \mathrm{~nm}$ region has been expanded 7 -fold.

Fig. 1. According to the Lambert-Beer law, for the same $\mathrm{Mb}$ solution, at any wavelength $(\lambda)$ the absorbance values of the deoxy- $\left(A_{\text {deoxy }}^{\mathrm{r}}\right)$ and CO-bound $\left(A_{\mathrm{CO}}^{\mathrm{r}}\right)$ forms of the reference spectra are correlated by Eq. (I):

$\frac{A_{\mathrm{CO}}^{\mathrm{r}}(\lambda)}{A_{\mathrm{deoxy}}^{\mathrm{r}}(\lambda)}=\frac{\varepsilon_{\mathrm{CO}}(\lambda)}{\varepsilon_{\mathrm{deoxy}}(\lambda)}$

In general, as previously shown (Beutler \& West, 1984), for a solution containing two absorbing forms, the absorbance at any wavelength can be expressed by the following relationship:

$A(\lambda)=A_{\text {deoxy }}(\lambda) \cdot\left(1-\chi_{\mathrm{CO}}\right)+A_{\mathrm{CO}}(\lambda) \cdot \chi_{\mathrm{CO}}$

where $A(\lambda)$ is the absorbance at a given wavelength, $A_{\text {deoxy }}(\lambda)=\varepsilon_{\text {deoxy }}(\lambda) \cdot b \cdot C$ is the absorbance of a deoxygenated solution of total concentration $C$ at a given wavelength, $A_{\mathrm{CO}}(\lambda)=\varepsilon_{\mathrm{CO}}(\lambda) \cdot b \cdot C$ is the absorbance of a $\mathrm{CO}-\mathrm{Mb}$ solution of total concentration $C$ at a given wavelength, $b$ is the path-length. $\chi_{\mathrm{CO}}$ is the relative amount of $\mathrm{CO}-\mathrm{Mb}$, defined as follows:

$\chi_{\mathrm{CO}}=\frac{C_{\mathrm{CO}}}{C_{\mathrm{CO}}+C_{\mathrm{deoxy}}}$

where $C_{\mathrm{CO}}$ and $C_{\text {deoxy }}$ are the concentration of CO-bound and deoxy- $\mathrm{Mb}$, respectively, with $C=C_{\mathrm{CO}}+C_{\text {deoxy }}$.

Measuring the absorbance at two different wavelengths (at 420 and $431 \mathrm{~nm}$ in the present case, corresponding to the absorption maxima of the $\mathrm{CO}-\mathrm{Mb}$ and deoxy-Mb, respectively) it is possible to calculate the relative amount of $\mathrm{CO}-\mathrm{Mb}\left(\chi_{\mathrm{CO}}\right)$ in the presence of deoxyMb Eq. (IV): 
$\chi_{\mathrm{CO}}=\frac{A(420) A_{\text {deoxy }}^{\mathrm{r}}(431)-A(431) A_{\text {deoxy }}^{\mathrm{r}}(420)}{A(420)\left[A_{\mathrm{deoxy}}^{\mathrm{r}}(431)-A_{\mathrm{CO}}^{\mathrm{r}}(431)\right]+A(431)\left[A_{\mathrm{CO}}^{\mathrm{r}}(420)-A_{\text {deoxy }}^{\mathrm{r}}(420)\right]}$

Substituting the measured absorbances of the reference spectra, we obtain the relative amount of $\mathrm{CO}-\mathrm{Mb} \chi_{\mathrm{CO}}$ Eq. (V)

$\chi_{\mathrm{CO}}=\frac{A(420) \times 0.78-A(431) \times 0.67}{A(420) \times 0.32+A(431) \times 0.55}$

\section{Results and discussion}

The chromophore and active site of $\mathrm{Mb}$ is the heme group which gives rise to two $\pi \rightarrow \pi^{*}$ electronic transitions at about $400 \mathrm{~nm}$ (Soret or B band) which is very intense (with an extinction coefficient of about $10^{4} \mathrm{M}^{-1} \mathrm{~cm}^{-1}$ ) and at $500-600 \mathrm{~nm}$ (Q bands). Since the wavelength maxima vary according to the oxidation, spin, and coordination states of the heme iron, the spectra of oxy-myoglobin, deoxy-myoglobin, met-myoglobin and CO-myoglobin can be distinguished by their peak positions and relative intensities (Adar, 1994). The electronic absorption spectra (Fig. 1) of met- (406, 502, and $631 \mathrm{~nm})$, oxy- $(414,542$, and $577 \mathrm{~nm})$, CO- $(420,538$, and $568 \mathrm{~nm})$, and deoxy(431 and $556 \mathrm{~nm}$ ) myoglobin purified from tuna fish clearly indicate that the Soret band red-shifts in the order metoxy-CO-deoxy. Moreover, in the visible region the distinctive wavelengths of the peaks enable us to distinguish the various $\mathrm{Mb}$ forms.

Fig. 2 shows the Soret band (top) and the corresponding second derivative (bottom) spectra for the various forms. The second derivative approach is usually applied in order

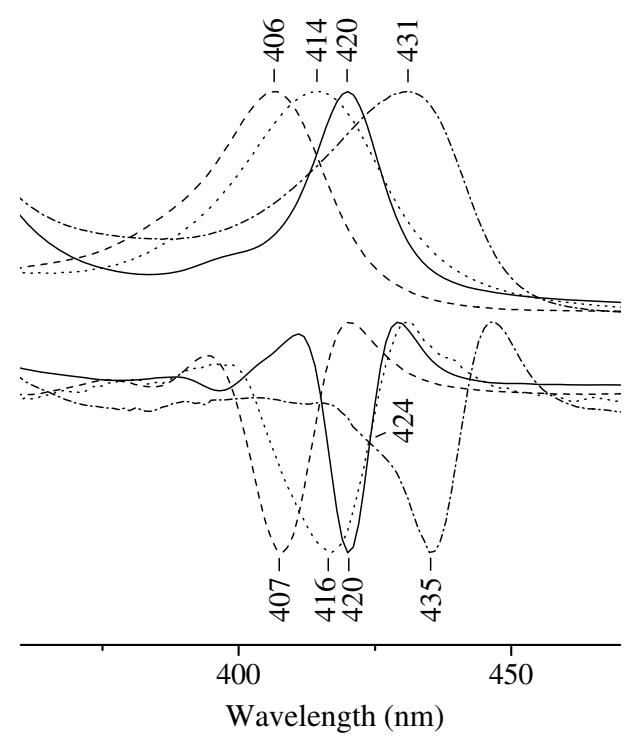

Fig. 2. Absorption and second derivative spectra in the Soret region of the

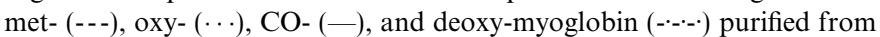
tuna fish. The arrow indicates the shoulder at $424 \mathrm{~nm}$. to better resolve broad bands (Vincieri, Coran, Bambagiotti-Alberti, Smulevich, \& Marzocchi, 1986). Derivative spectrophotometry consists in the differentiation of the electronic absorption spectrum and allows one to improve the resolution of mixtures, because it enhances the detectability of minor spectral features. In fact, it reveals subtle spectral features by presenting them in a new and visually more accessible way, allowing the resolution of multi-component elements, and reducing the effect of spectral background interference (Ojeda \& Rojas, 2004, and references therein). It consists of calculating and plotting the second mathematical derivative of an electronic absorption spectral curve. The most characteristic feature of the second-order derivative is a negative band with the minimum corresponding to the maximum of the electronic absorption spectrum. From Fig. 2, it can be seen that a minimum is observed at a wavelength corresponding to the Soret maximum, at $407 \mathrm{~nm}$ (met-Mb), $416 \mathrm{~nm}$ (oxy$\mathrm{Mb}$ ), $420 \mathrm{~nm}(\mathrm{CO}-\mathrm{Mb})$, and $435 \mathrm{~nm}$ (deoxy-Mb), respectively. In general, the Soret band is a very sharp band. The only exception is represented by the deoxy-form which shows a second minimum at $424 \mathrm{~nm}$.

Fig. 3 compares the Soret region in the UV-Vis (panel A) and the second derivative (panel B) spectra obtained for meat drip collected from nine different samples of defrosted yellowfin tuna loins. The Soret maxima (Fig. 3, panel A) vary among the various samples between 412 (sample 4) and $420 \mathrm{~nm}$ (sample 8). In addition, the electronic absorption bands are very broad suggesting the presence of various species, which can be resolved by the second derivative spectra (panel B). In particular, sample 4 reveals the presence of both the met-form $(407 \mathrm{~nm})$ and the CO ligated form $(420 \mathrm{~nm})$, whereas samples 1,3 , and 6 do not give a clear indication of the presence of $\mathrm{Mb}$ $\mathrm{CO}$ since they are characterized by a broad band centred at $416-419 \mathrm{~nm}$. On the contrary, samples $2,5,7,8$, and 9 show an intense main peak between around $420 \mathrm{~nm}$, characteristic of $\mathrm{Mb}-\mathrm{CO}$ complex. These data clearly indicate that the tuna fish meat has been previously treated with $\mathrm{CO}$, despite that it was not labelled as such. The different amount of $\mathrm{CO}$ found in the various samples can be certainly related to the variable exposure of the specimens to air, which slowly removes CO-bound to myoglobin, replacing it with oxygen and eventually forming the met-form.

To identify unambiguously the $\mathrm{CO}-\mathrm{Mb}$ and to calculate the relative amount of $\mathrm{CO}-\mathrm{Mb}$, expressed as the percentage $\chi_{\mathrm{CO}}(\%)$, we chemically reduced the solution under anaerobic conditions (see Section 2). In this manner the ferric met$\mathrm{Mb}$ is reduced to ferrous deoxy-Mb with the concomitant red-shift of the Soret band from 406 to $431 \mathrm{~nm}$ (Fig. 1), whereas the $\mathrm{CO}-\mathrm{Mb}$ adduct content is not expected to vary. 

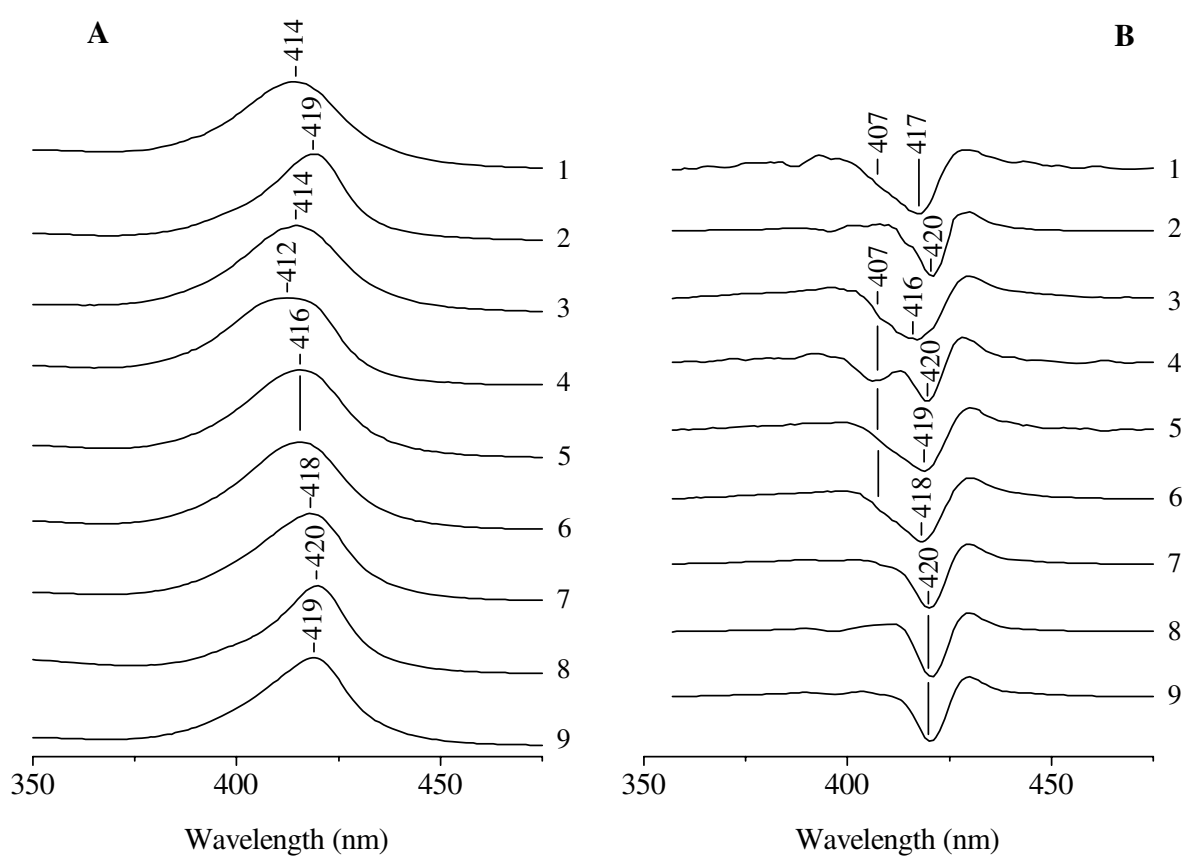

Fig. 3. Absorption and second derivative spectra of meat drip from nine samples of defrosted tuna fish loins diluted in deoxygenated phosphate buffer.

Fig. 4 compares the UV-Vis and the second derivative spectra of the nine samples after reduction by dithionite. As expected, the ferric and the oxy-forms disappear and are replaced by the ferrous species resulting in a red-shift of the Soret band. These changes are particularly evident in the second derivative spectra where the minimum at $407 \mathrm{~nm}$ (met-Mb, Fig. 3, panel B) disappears and it is replaced by a new minimum at $435 \mathrm{~nm}$ (deoxy-Mb, Fig. 4, panel B). Before and after the reduction, a minimum at $420 \mathrm{~nm}$, due to the $\mathrm{CO}-\mathrm{Mb}$ adduct, is clearly observed in the majority of the samples, allowing us to confirm that the fish meat has been treated with carbon monoxide gas. However, the spectra clearly indicate that the samples 1 and 3 have lost the $\mathrm{CO}$ content since the UV-Vis are typical of deoxy-Mb (see Fig. 1 for comparison). The quantitative analysis (Table 1) confirmed this conclusion. Moreover, from the reference spectra (on 10 replicate samplings) of the deoxy- $(0 \%$ of $\mathrm{CO}-\mathrm{Mb})$ and $\mathrm{CO}$-bound form
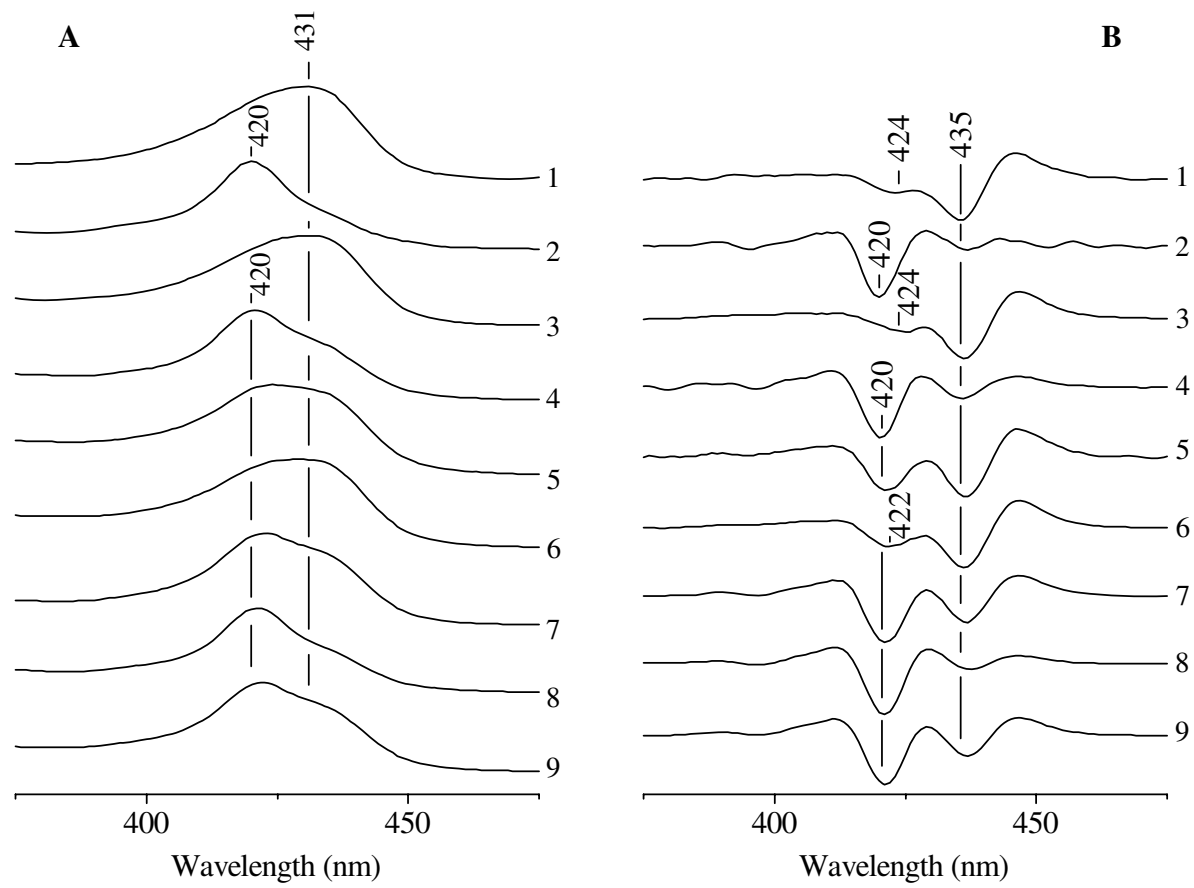

Fig. 4. As Fig. 2, after addition of dithionite as reducing agent. 
Table 1

Absorbances at $420 \mathrm{~nm}[A(420)]$ and $431 \mathrm{~nm}[A(431)]$ of the reference samples (see Fig. 1) and of tuna fish meat drip (see Figs. 4 and 5), their ratio, and relative amount of $\mathrm{CO}-\mathrm{Mb}$ expressed as the percentage $\chi_{\mathrm{CO}}(\%)$

\begin{tabular}{llllr}
\hline & $A(420)$ & $A(431)$ & $\frac{A(420)}{A(431)}$ & $\begin{array}{r}\chi_{\mathrm{CO}} \\
(\%)\end{array}$ \\
\hline $\begin{array}{l}\text { Deoxy-Mb } \\
\quad \text { (reference, from Fig. 1) }\end{array}$ & 0.67 & 0.78 & $0.86 \pm 0.01$ & 0 \\
CO-Mb (reference, Fig. 1) & 1.22 & 0.46 & $2.65 \pm 0.01$ & 100 \\
Untreated-sample (from Fig. 5) & 1.32 & 1.50 & 0.88 & 2.0 \\
Treated sample 1 (from Fig. 4) & 0.23 & 0.26 & 0.88 & 2.4 \\
Treated sample 2 (from Fig. 4) & 2.00 & 1.08 & 1.85 & 67.8 \\
Treated sample 3 (from Fig. 4) & 1.42 & 1.61 & 0.88 & 2.2 \\
Treated sample 4 (from Fig. 4) & 0.79 & 0.56 & 1.41 & 43.0 \\
Treated sample 5 (from Fig. 4) & 0.21 & 0.21 & 1.00 & 12.6 \\
Treated sample 6 (from Fig. 4) & 1.15 & 1.24 & 0.93 & 6.3 \\
Treated sample 7 (from Fig. 4) & 1.21 & 1.06 & 1.14 & 24.1 \\
Treated sample 8 (from Fig. 4) & 0.99 & 0.65 & 1.52 & 49.9 \\
Treated sample 9 (from Fig. 4) & 1.45 & 1.20 & 1.21 & 29.1 \\
\hline
\end{tabular}

( $100 \%$ of $\mathrm{CO}-\mathrm{Mb})$ of tuna $\mathrm{Mb}$ we can calculate the $A(420) /$ $A(431)$ average ratio. In the absence of $\mathrm{CO}$, the ratio is $0.86 \pm 0.01$. For a fully bound $\mathrm{CO}-\mathrm{Mb}$ sample the $A(420) / A(431)$ ratio is $2.65 \pm 0.01$. The level of confidence was calculated with a probability $p=95 \%$ in both cases.

To evaluate the validity of the proposed method, 10 replicates of three different series of treated (fortified) and nonCO-treated samples (untreated) have been tested; the results are reported in Table 2 . The precision has been evaluated by the relative standard deviation (RSD) of CO concentration. Our RSD values are of the same order of magnitude as those reported by Anderson and $\mathrm{Wu}$ (2005), obtained on the basis of the gas chromatography/ mass spectrometry method. According to the IUPAC definition, the detection limit (LOD) is given by $y_{\mathrm{B}}=\frac{A^{(4420)}}{A(431)}+3 s$, which, for the untreated sample, is 0.89 . Therefore, in agreement with previous findings (Beutler \& West, 1984), the \% of CO-Mb can be calculated directly from the ratio of the absorbance values at 420 and $431 \mathrm{~nm}$. We conclude that any ratio $>0.89$ indicates that the product has been exposed to CO.

Fig. 5 shows the electronic absorption spectra obtained for meat drip collected from fresh yellowfin tuna loins, that have not been CO-treated, fished close to Sardinia (Italy) and kept in the refrigerator for $36 \mathrm{~h}$. The second derivative spectrum of the Soret band is also shown (dashed line). The

Table 2

Average $y_{\mathrm{B}}=\frac{A(420)}{A(431)}$ between 10 replicate samplings of the ratio of the absorbance value at $420 \mathrm{~nm}[A(420)]$ and $431 \mathrm{~nm}[A(431)]$ for untreated and three different fortified samples (see text)

\begin{tabular}{llllllll}
\hline Samples & $A(420)$ & $A(431)$ & $y_{\mathrm{B}}=\frac{A(420)}{A(431)}$ & $s$ & $\begin{array}{l}\chi_{\mathrm{CO}} \\
(\%)\end{array}$ & $\begin{array}{l}s_{\%} \\
(\%)\end{array}$ & $\begin{array}{l}\text { RSD } \\
(\%)\end{array}$ \\
\hline Untreated & 0.80 & 0.93 & 0.86 & 0.01 & 0 & - & - \\
CO-fortified 1 & 0.35 & 0.34 & 1.03 & 0.01 & 15.1 & 1.1 & 7.3 \\
CO-fortified 2 & 0.95 & 0.80 & 1.19 & 0.03 & 27.6 & 2.1 & 7.6 \\
CO-fortified 3 & 0.77 & 0.62 & 1.24 & 0.06 & 31.5 & 3.9 & 12.4 \\
\hline
\end{tabular}

$s$ is the standard deviation, $\chi_{\mathrm{CO}}(\%)$ is the relative amount of $\mathrm{CO}-\mathrm{Mb}$ expressed as the percentage, $s_{\gamma}$ is its standard deviation, and RSD is the relative standard deviation.

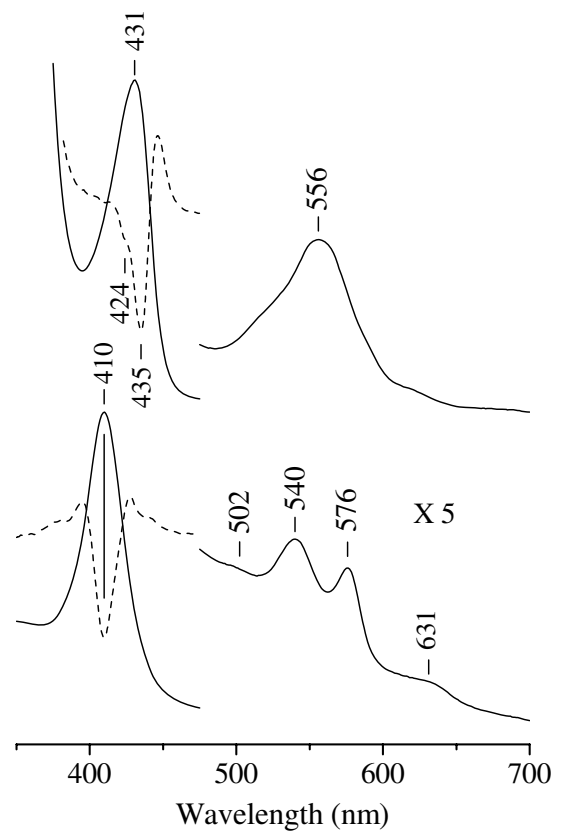

Fig. 5. Lower trace: absorption and second derivative spectra (-----, in the Soret region) of meat drip from fresh tuna fish loins diluted in deoxygenated phosphate buffer. Upper trace: absorption and second derivative pectra (--.---, in the Soret region) of meat drip from fresh tuna fish loins diluted in deoxygenated phosphate buffer in the presence of dithionite as reducing agent. The $475-700 \mathrm{~nm}$ region has been expanded 5fold.

wavelength maximum of the Soret band at $410 \mathrm{~nm}$ suggests the presence of a mixture of oxy- and met-forms. This is confirmed by the visible region where bands at 540 and $576 \mathrm{~nm}$ are indicative of the oxy-form and the weak bands at 502 and $631 \mathrm{~nm}$ confirm the presence of the met-form (see Fig. 1). Accordingly, no $\mathrm{CO}-\mathrm{Mb}$ has been detected by the quantitative analysis $\left(\frac{A(420)}{A(431)}=0.88\right)$ upon reducing the sample (Table 1).

\section{Conclusions}

CO-treated tuna fish is characterized by an abnormal cherry colour. Visual inspection and electronic absorption spectra can provide immediately information about the presence of $\mathrm{CO}-\mathrm{Mb}$ complexes. Moreover, the subsequent combined analysis of the electronic absorption spectra in their normal and second derivative modes gives an unequivocal determination of the presence of $\mathrm{CO}$ in the defrosted meat drip of tuna loins. A characteristic maximum at $420 \mathrm{~nm}$, corresponding to a minimum in the second derivative spectrum at the same wavelength, is observed due to the Soret band of the CO-Mb adduct.

Small amounts of $\mathrm{CO}$ adduct, in the presence of met-Mb and oxy-Mb, can be clearly revealed by chemically converting the met- and oxy-forms to the deoxy-form in an anaerobic environment. In this way the Soret bands of the met- and oxy-forms, which overlap to some extent with the Soret of the CO complex, are red-shifted upon reduction of the protein to the deoxy-form. As a consequence 
the Soret of the $\mathrm{CO}$ adduct is clearly visible as $\mathrm{CO}$ forms a very stable complex and it is not easily detached upon reduction of the protein under anaerobic conditions.

The percentage of $\mathrm{CO}-\mathrm{Mb}$ can be calculated directly from the ratio of the absorbance values at 420 and $431 \mathrm{~nm}$.

These considerations underline the suitability of this method to detect even small amounts of the $\mathrm{CO}-\mathrm{Mb}$ adduct in fish tissue, in regard to the fraudulent treatment of fish in the modified atmosphere packaging system. It could be used as a rapid and low cost laboratory screening method for food control. Moreover, the method reveals the presence in the tissue of the met-Mb form, which is an important parameter in the evaluation of the aging of the fish sample, since it is formed upon oxidation by air of the oxy-form.

\section{Acknowledgement}

This work is supported by Italian Ministry of Health (IZS.LT-16/04RC).

\section{References}

Adar, F. (1994). Electronic absorption spectra of hemes. In D. Dolphin (Ed.). The Porphyrins, Physical Chemistry, Part A (Vol. III, pp. 167-206). New York: Academic Press, 235.

Anderson, C. R., \& Wu, W.-H (2005). Analysis of carbon monoxide in commercially treated tuna (Thunnus spp.) and Mahi-Mahi (Coryphaena hippurus) by gas chromatography/mass spectrometry. Journal of Agricultural and Food Chemistry, 53, 7019-7023.

Antonini, E., \& Brunori, M. (1971). In A. Neuberger \& E. L. Tatum (Eds.), Hemoglobin and myoglobin in their reactions with ligands. Frontiers of Biology (Vol. 21). Amsterdam: North-Holland Publ. Co..

Beutler, E., \& West, C. (1984). Simplified determination of carboxyhemoglobin. Clinical Chemistry, 30, 871-874.

Bylkas, S. A., \& Andersson, L. A. (1997). Microburger biochemistry: extraction and spectral characterization of myoglobin from hamburger. Journal of Chemical Education, 74, 426-430.

Cruz, A., López-Rivadulla, M., Sánchez, I., Bermejo, A. M., \& Fernández, P. (1993). Simultaneous determination of carboxyhemoglobin and total hemoglobin in carbon monoxide intoxicated patients by use of third-derivative spectrophotometry. Analytical Letters, 26(6), $1087-1097$.
Giddings, G. G. (1974). Reduction of ferrimyoglobin in meat. CRC Critical Reviews in Food Technology, 5, 143-173.

Levine, B., D’Nicuola, J., Kunsman, G., Smith, M., \& Stahl, C. (1996). Methodologic consideration in the interpretation of postmortem carboxyhemoglobin concentrations. Toxicology, 115, 129-134.

Lewis, R. J., Johnson, R. D., \& Canfield, D. V. (2004). An accurate method for the determination of carboxyhemoglobin in postmortem blood using GC-TCD. Journal of Analytical Toxicology, 28(1), 59-62.

Livingston, D. J., \& Brown, W. D. (1981). The chemistry of myoglobin and its reactions. Food Technology, 25(3), 244-252.

Lunõ, M., Roncales, P., Djenane, D., \& Beltrán, J. A. (2000). Beef shelf life in low $\mathrm{O}_{2}$ and high $\mathrm{CO}_{2}$ atmospheres containing different low $\mathrm{CO}$ concentrations. Meat Science, 55, 413-419.

Ojeda, C. B., \& Rojas, F. S. (2004). Recent developments in derivative ultraviolet/visible absorption spectrophotometry. Analytica Chimica Acta, 518, 1-24.

Oritani, S., Zhu, B.-L., Ishida, K., Shimotouge, K., Quan, L., Fujita, Q. M., et al. (2000). Automated determination of carboxyhemoglobin contents in autopsy materials using head-space gas chromatograhy/ mass spectrometry. Forensic Science International, 113, 375-379.

Sano, Y., \& Hashimoto, K. (1958). Studies on the Discoloration in Fish Meat during Freezing Storage. Bulletin of the Japanese Society of Scientific Fisheries, 24, 519-523.

Shalaby, A. R. (1997). Significance of biogenic amines to food safety and human health. Food Research International, 29(7), 675-690.

Silla Santos, M. H. (1996). Biogenic amines: their importance in foods. International Journal of Food Microbiology, 29, 213-231.

Sørheim, O., Nissen, H., \& Nesbakken, T. (1999). The storage life of beef and pork packaged in an atmosphere with low carbon monoxide and high carbon dioxide. Meat Science, 52, 157-164.

Tajima, G., \& Shikama, K. (1987). Autoxidation of oxymyoglobin. An overall stoichiometry including subsequent side reaction. Journal of Biological Chemistry, 262, 12603-12606.

Verde, C., Howes, B. D., De Rosa, M. C., Raiola, L., Smulevich, G., Williams, R., et al. (2004). Structure and function of the Gondwanian hemoglobin of Pseudaphritis urvillii, a primitive notothenioid fish of temperate latitudes. Protein Science, 13, 2766-2781.

Vincieri, F. F., Coran, S. A., Bambagiotti-Alberti, M., Smulevich, G., \& Marzocchi, M. P. (1986). Second-derivative UV spectra of polyacetylene chromophores. fingerprint of their geometrical isomers. Chemische Berichte, 119, 2843-2847.

Wittenberg, J. B., \& Wittenberg, B. A. (1981). In E. Antonini, L. RossiBernardi, \& E. Chiancone (Eds.). Methods in Enzymol (Vol. 76, pp. 29-42). New York: Academic Press.

Wolfe, S. K., Watts, D. A., \& Brown, W. D. (1978). Analysis of myoglobin derivatives in meat or fish samples using absorption spectrophotometry. Journal of Agricultural and Food Chemistry, 26, 217-219. 